\title{
Specimen records of Oarisma Scudder 1872 (Lepidoptera: Hesperiidae) in the Oregon State Arthropod Collection, OSU, Corvallis OR
}

\author{
Jon H. Shepard
}

Christopher J. Marshall

Oregon State Arthropod Collection, Department of Integrative Biology, Oregon State University, Corvallis OR 97331

\begin{abstract}
A dataset of 260 skipperling specimens belonging to the genus Oarisma is presented along with information pertaining to how the label data was digitized and the metadata standards adopted. A brief synopsis of the dataset is provided along with a supplemental .csv file containing the data records themselves.

Cite this work, including the attached dataset, as:

Shepard, J. H, C. J. Marshall. 2017. Specimen records of Oarisma Scudder 1872 (Lepidoptera: Hesperiidae) in the Oregon State Arthropod Collection, OSU, Corvallis, OR.. Catalog: Oregon State Arthropod Collection 1(1) p.1-3. http://doi.org/10.5399/osu/Cat OSAC.1.1.3995
\end{abstract}

\section{Introduction}

In 2016, as part of LepNet (Seltmann et. al., 2017) - a national effort to create digital records for North American Lepidoptera - the Oregon State Arthropod Collection began digitizing label data associated with its butterfly and moth collection. While most of the Hesperiidae has not yet been digitally captured a concerted effort was launched across the LepNet participants to see if we could rapidly generate a dataset for Oarisma with the aim of assisting conservation efforts for Oarisma poweshiek (Parker, 1870; Fig 1) being led by Dr. Anna Monfils at Central Michigan University. The dataset published herein contains the label data for all specimens residing at the Oregon State Arthropod Collection as of August 2017.

\section{Methods}

All specimens are given unique serial number (catalog number) that are printed using a machinereadable barcodes as well as a human readable numerals on an acid-free card-stock labels that are placed as the bottom-most label.

Data standards: All label data is consistent with Darwincore standards for occurrence data (http: / rs.tdwg.org/dwc/terms/Occurrence).

Taxonomic treatment: the taxonomic identity for all specimens was re-confirmed prior to digitization. To ensure nomenclatural validity, all names were checked and standardized according to Pelham (2008).

Locality and georeference data. Locality data was transcribed into the DublinCore location fields (http:/ / purl.org/dc/terms/Location). Namely: country, stateProvince, county and locality. Missing information (e.g., no county printed on actual specimen label) was added to a record if it could be determined without ambiguity based on gazetteers, maps or in reference to other label data. Elevational data on labels were converted to minimumDistanceAboveSurfaceInMeters. Elevational ranges (e.g, 500-1200m) were recorded as the lower of the two. When available, decimalLatitude and decimalLongitude were included, but not all records were georeferenced at this time. 
Metadata: BasisofRecord for each occurrence was entered as preservedSpecimen with the collector(s) listed on the label stored in the recordedBy field. The OccurrenceID is a URI for the specimen record itself, and includes the catalog number: "http: / / osac.oregonstate.edu/SP/OSAC_XXXXXXXXXX" where "XXXXXXXXXX" is the 10-digit unique catalog number for the specimen.

\section{Results}

Two hundred and sixty specimens identified as Oarisma were located, belonging to three species: O. poweshiek (Parker, 1870), O. garita (Reakirt, 1866), O. edwardsii (Barnes, 1897).

Not surprisingly, the majority of specimens belonged to $O$. garita which occurs throughout the Pacific Northwest (Guppy \& Shepard, 2001). Fourteen records for the endangered species, O. poweshiek were found (Fig 1.) from two localities, one in Michigan and one in Iowa, all from the 1970's and 1980's.

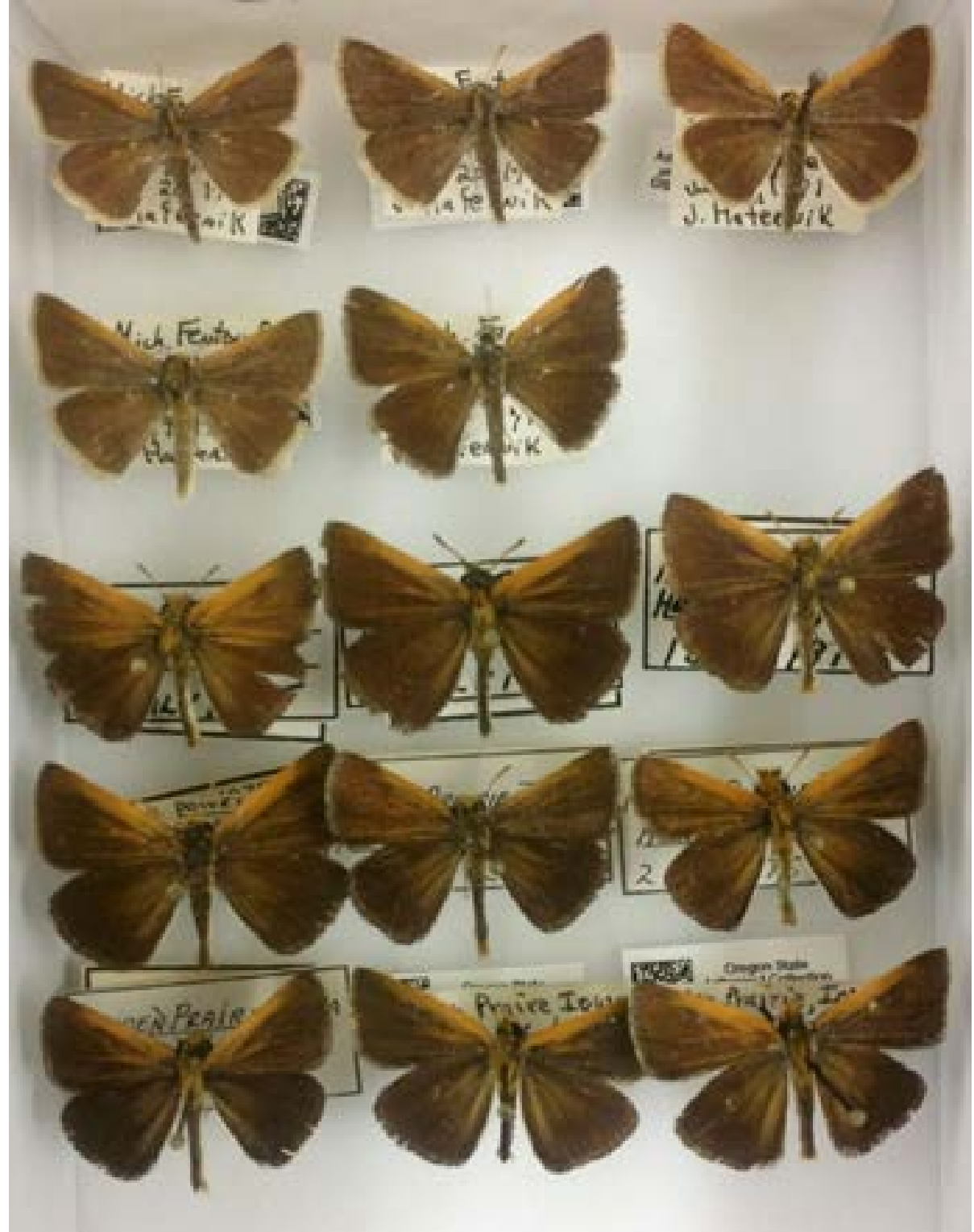

Figure 1. Oarisma poweshiek specimens in the Oregon State Arthropod Collection. From top left: OSAC 0001011091, OSAC 0001011092, OSAC 0001011099, OSAC 0001011090, OSAC 0001011088, OSAC 0000084234, OSAC 000084245, OSAC 000004232, OSAC 000004261 OSAC 000004258
Discussion

With only two localities and 14 specimens the OSAC's holdings may seem meager in the face of understanding present day distributional information for the endangered O. poweshiek. Perhaps the distributional records for its PNW congener, O. garita, for which the OSAC has much better coverage, may provide useful clues in the distribution of its eastern relative. It is hoped, that once these records are combined with those of other institutions, the larger dataset might provide more insights still.

\section{Acknowledgements}

This work was accomplished as part of NSF DBI ADBC Award \#1601888: Digitization TCN:

Collaborative Research: Lepidoptera of orth America Network: Documenting Diversity in the Largest Clade of Herbivores. This work was also made possible in part by the many years of curatorial work in the OSAC by Dr. Paul Hammond.

\section{References}

Guppy, C. S. \& J. H. Shepard. 2001. Butterflies of British Columbia, including western Alberta, southern Yukon, the Alaska panhandle, Washington, northern Oregon, northern Idaho, and northwestern Montana. UBC Press, Vancouver, British Columbia. 414 pp.

Pelham, J.P. 2008. A catalogue of the butterflies of the United States and Canada. Journal of Research on the Lepidoptera 40: 1-658

Seltmann, K. C. et al. 2017. LepNet: The Lepidoptera of North America Network. Zootaxa 4247 (1): 073-077. http://doi.org/10.11646/zootaxa.4247.1.10 